\title{
Screening for gynaecological cancers
}

Kalsi J, Manchanda R, Menon U.

Affiliation: Gynaecological Cancer Research Centre, Department of Women's Cancer, Institute for Women's Health, Univeristy College London

\begin{abstract}
An estimated $17 \%$ of all new cancers in women worldwide are due to cancers of the cervix, the ovary and the uterus. Together these cancers account for $14.6 \%$ of all female cancer deaths. This is a significant societal and economic burden which can be limited through cancer screening. In the developed world marked reductions of 50\%-90\% in disease rates have been observed as a result of cervical cancer screening. In contrast in developing countries, where more than $85 \%$ of all new cases and deaths from this cancer are reported, significant challenges need to be overcome.. Although cytology remains a key component of cervical screening, the newer molecular tests offer a more targeted, risk-attuned approach. The situation for the other two gynaecological cancers is different. The case for ovarian cancer screening has yet to be made, with the results of key screening trials in high- and low-risk populations still pending. Screening for endometrial cancer is traditionally not advocated as women become symptomatic during the earlier, treatable stages of disease. However, consideration of screening options for these two cancers is warranted since endometrial cancer rates are on the increase with women and in ovarian cancer the high case fatality ratio remains unchanged.
\end{abstract}

Keywords: Cervical, Ovarian, Endometrial, Gynaecological Cancer, Screening

\section{Main article}

\section{Introduction}

The most commonly occurring gynaecological cancers are those affecting the cervix, the ovary and the womb. Figures released by Globocan [201] show that these cancers accounted for an estimated $17 \%$ of all new cancer cases in women worldwide and $14.6 \%$ of all female cancer deaths in 2008. As the world population expands, ages, and increasingly adopts lifestyles which may be detrimental to health, the global rates of cancer are expected to rise [1]. For gynaecological cancers this could mean an estimated increase in incidence and mortality rates of $66 \%$ and $62 \%$ respectively by 2030 , based on anticipated population growth and current trends [201]. There is significant need to invest in and refine measures to limit this potential growth, especially in low - middle income countries (LMIC) where cancer impact is expected to be the greatest and where resources are limited and societal norms may in addition, engender inequalities in women's healthcare. One strategy for managing the disease burden is through screening asymptomatic individuals for the presence of early/preinvasive disease. This approach has already produced considerable success in reducing cervical cancer rates by $50-90 \%$ in the industrialised countries [2]. However, 
cervical cancer still remains a key public healthcare concern in the LMIC countries. In this article we review the current burden of the common gynaecological cancers, the unique challenges each of these conditions pose and the approaches that are used for screening and early detection of disease.

\section{Cervical cancer}

Cervical cancer is the third most commonly diagnosed cancer and the fourth leading cause of death in women worldwide [201,1]. An estimated 275,000 deaths and 529,800 new cases were attributed to this disease in 2008 , with the majority of new cases $(453,300)$ and deaths $(242,000)$ being observed in the developing nations. The highest incidences were in Africa (Eastern (age-standardised rate (ASR) 34.5), Western (33.7) and Southern regions (26.8), South-Central Asia (24.6) and South America (23.9) per 100,000. The lowest incidences were reported in North America, New Zealand/Australia, with ASRs of 5.7 and 5.0 per 100,000 respectively. For mortality, the ASRs per 100,000 were 25.3 and 24.0 for Eastern and Western Africa respectively compared to 2.0 for Western Europe, 1.7 for North America and 1.4 for Australia/New Zealand per 100,000.

The differences in cancer rates between the industrialised nations and the developing world reflect the lack of well organised screening programmes in the latter nations. [3]. Poverty, lack of education and access to medical care are all contributory factors to high level of cervical cancer cases and deaths in the developing countries. The cancer is often diagnosed at a late stage and the infrastructure may not exist to provide timely or appropriate treatment. In developed countries disparities may be observed in women from the medically underserved communities [4]. Approximately $50 \%$ of all cervical cancer cases in the US are in women who have never been adequately screened [5].

Cervical cancer, which meets most of the WHO criteria for screening (Table 1) [6] is the only gynaecological cancer for which mass screening programmes exist. These are either centrally managed and based on computerised call /recall systems as in the United Kingdom [UK] and some European countries or are opportunistic as in the USA and Canada. The key to success is adequate coverage, high quality screening programmes, and access to treatment.

Cervical cancer typically develops over 2-3 decades with changes beginning in the transformation zone of the cervix. Histologically, the pre-cancerous changes are termed cervical intraepithelial neoplasia (CIN). In CIN1, which is classed as a low grade lesion, nuclear atypia is seen in the lower third of the epithelium. There may be polyploidy and bi or multinucleated cells, mitotic figures and a variety of cytopathic effects indicative of a viral infection and are especially prominent in CIN1[7].

CIN2 and CIN3 are classed as high grade lesions. In these lesions, atypia is present in all layers of the squamous epithelium to an extent and degree far exceeding CIN1. Other features include increased nuclear cytoplasmic ratio and hyperchromatic nuclei. Immature basal-type cells typically occupy more than the lower third of the epithelium. In CIN2, the lower two thirds of the epithelium are occupied by neoplastic basaloid cells. In CIN3 there is further expansion of cellular changes with immature basaloid cells occupying the upper third 
of the cervical epithelium. CIN3 is also referred to by some as stage 0 carcinoma / carcinoma in situ. Both high and low grade CIN lesions can co-exist and not all CIN, including CIN3 progress to invasive carcinoma.

The large majority of lesions, especially CIN1, regress spontaneously or remain stable. Recent re-evaluation of data derived from an unethical study conducted in New Zealand during the 1960s and 70s, where treatment was withheld or delayed in CIN3+ women, showed that $30-50 \%$ of CIN3 will progress to malignancy over a 30 year period [8].

The confirmation in the 1980s that the causative agent for cervical cancer was Human Papilloma Virus (HPV) was a landmark event which changed the landscape for primary and secondary prevention of this disease $[9,10]$. HPVs are small, unenveloped DNA viruses that are common in both men and women and are transmitted mainly through sexual contact or skin-to skin contact. HPVs exhibit species and tissue trophism and of the 120 genotypes identified from human tissue, over 40 genotypes have the ability to infect the human genital tract $[11,12]$. Fifteen of these have been identified as high risk for cervical cancer [13] and twelve [HPVs 16, 18, 31, 33, 35, 39, 45, 51, 52, 56, 58 and 59] are already classed as carcinogens by WHO [14]. A recent cross sectional study involving 38 countries demonstrated that HPV16 and HPV18 [15] are the most prevalent of all genotypes in all regions and responsible for $71 \%$ of all cervical cancer cases. HPV16, HPV18 and HPV45 jointly were responsible for $94 \%$ of adenocarcinomas.

Infection rates are high soon after onset of sexual activity and women can be simultaneously infected with multiple types at any one time. Infection by itself does not lead to cancer and in many cases is cleared within 1-2 years [12] and the women may not even be aware that they are infected as there are no symptoms. A key risk factor for cancer development is persistence of infection with oncogenic types. It is still not fully understood what allows viral persistence but the prominence of HPV16 may be related to its ability to persist for a longer period than other types [12]. Two oncoproteins closely associated with the tumoriogenic process are $\mathrm{E} 6$ and $\mathrm{E} 7$. These are significant in disrupting the normal functioning of tumour suppressors p53 and pRb, causing loss of cell cycle control and producing genetic instability $[16,17]$. Overexpression of these oncoproteins is associated with an increased risk of disease progression. The oncoprotein E5 augments their function and supports tumour progression [17]

Risk cofactors for development of cervical cancer are smoking, long term use of contraceptives, multiparity, multiple partners early age of sexual activity, and co-infection with other STD related microorganisms [eg Chlamdyia] [202] (Ref 202). Individuals who are immunocompromised, for example in HIV or organ transplant recipients, are at 2-3 times greater risk for cervical cancer and may need to be screened more frequently.

\section{Cervical cytology}

Exfoliative cytology remains the primary means of testing in many countries $[202,18]$ though recent developments allow for molecular testing as part of a co-testing strategy or for triage of abnormal findings. The mainstay for screening for decades has been the Papanicoloau test which was first described in the 1940s [19]. Though widely used and exhibiting high specificity, the test is not very sensitive, with these being estimated at the threshold of atypical cells of undetermined significance [ASCUS] at 98\% (95\% Cl 97\%-99\%) and 51\% (95\% Cl 37\%-66\%) respectively [20]. In a meta-analysis of 62 studies, specificity of 
conventional cytology ranged between $14 \%-97 \%$ and sensitivity between $11-99 \%$ [21].The assay is prone to sampling errors and air drying artefacts. The reading of the slides and interpretation of the results is subjective with detection errors. These shortcomings are thought to underlie the lower sensitivities (high false negative rates) reported with this assay in many countries $[22,23]$.

In an attempt to resolve these problems liquid based cytology (LBC) was introduced in the mid-1990s-2000s [24,25]. It involves samples being collected from the transformation zone of the cervix using a special brush and placed into a fixative liquid. An automated process prepares a thin layer of cells on a slide which is then stained for analysis. The use of ThinPrep was approved by the FDA in 1996 [25]. Other commercially available LBC systems include SurePath, Cytoscreen and Labonard Easy Prep. Reading of the slides can also be automated using the ThinPrep Imaging System (Hologic, Bedford, MA, USA) or the FocalPoint GS Imaging System (BD Diagnostics,Franklin Lakes, NJ, USA). The recent MAVARIC trial however, reports that automation-assisted reading is $8 \%$ less sensitive than manual reading [26].

In the UK LBC was recommended as the primary test in the NHS cervical screening programme in England and Wales by the National Institute for Clinical Excellence (NICE) in 2003 [27]. The changeover to this technology was completed in 2008 [202]. Compared to Pap-smears, LBC is associated with fewer inadequate/ unsatisfactory smears and in initial studies had higher sensitivity for abnormal smears However, a recent meta-analysis which used gold standard verification, based on colposcopy and histology of colposcopy-targeted biopsies, found no significant difference in sensitivity and specificity for histologically confirmed CIN 2 or worse between LBC and traditional pap-smears [28].

Various systems exist for reporting cytology results (Table 2). The Bethseda System (TBS) first proposed in 1988 and subsequently revised in 1991 and 2001 is employed in the USA [29]. In the United Kingdom the British Society of Clinical Cytology (BSCC) terminology for reporting cervical cytology results was first described in 1986 [30] with recommendations for amendments being made recently [31,32]. In the original system dyskaryotic cells were classified as mild, moderate, or severe according to the nuclear and cytoplasmic ratios and the degree of morphological abnormalities. The new proposed changes to the terminology in the UK are more closely aligned with TBS. Any abnormal result is followed by colposcopy and biopsy as per local guidelines and diagnosis is made on histological analysis.

\section{Visual Inspection tests}

Screening with cytology based assays requires a well organised, resource intense infrastructure which is expensive to run. In addition, it relies on women being able to return to the clinic for repeat testing or treatment. As a result other methodologies have been developed for use in low-resource settings $[33,34]$. These are mainly tests that rely on visual inspection of the cervix. This can be performed after application of 3-5\% acetic acid (VIA), visual inspection with a magnifying glass (VIAM), visual inspection after Lugol's iodine (VILI). VIA is the most frequently used option and involves application of dilute acetic acid to the cervix with a cotton swab or a spray followed a minute later by scanning the transformation zone with the aid of a bright light for areas of acetowhitening. The results are classed as positive or negative depending on extent of the acetowhitening using defined criteria [34]. However, interpretation of results may be difficult where the area of transformation zone is 
poorly visible or in postmenopausal women because of degenerative changes in the cervical epithelium. The advantages of this test are that it is fast, cheap and results are immediately available and the screening personnel can be trained within a matter of weeks. However, the test is subjective and results are variable and not always reproducible if quality assurance procedures are not standardised. The reported sensitivity and specificity ranges are wide, 31-95\% and 49-97\% respectively, with PPV of 5-20\% and NPV 92-99\% [34].

Comparisons of studies have been hampered because of the use of different disease thresholds and variable access to confirmatory diagnosis. A recent comprehensive metaanalysis [35] identified 77 cross sectional studies using VIA. In 26 of these studies where the results were confirmed histologically in all screened women, the technique had a sensitivity of $80 \%$, specificity of $92 \%$ with a PPV of $10 \%$ and NPV $99 \%$. In other investigations where VIA has been compared with cytology the sensitivity of VIA has been reported to be equivalent or higher but the specificity lower than cytology In a cluster, randomized, controlled trial in India a single round of VIA, followed by immediate colposcopy and treatment produced a significant reduction (35\%) in mortality at 7 years [36]

\section{HPV testing}

The observation that virtually all cervical cancer cases (99.7\%) are due to HPV focused attention on the detection of viral DNA [37]. Several assays for HPV have been developed. Mostly these are DNA hybridisation or PCR based assays. One of the earliest second generation tests approved by the FDA was the Hybrid Capture 2 (HC2) assay Qiagen, Gaithersburg, MD, USA) in 2003. This test detects 13 high risk (HR) HPV types and has been used as a comparator for the development of a number of the newer assays, which measure presence of $14 \mathrm{HR}$-HPV types and/or also separately determine levels of HPV16 and 18 expression. These tests include FDA approved Cervista HPV HR test and Cervista HPV 16/18 (Hologic Inc, Madison, WI, USA), Roche's Cobas 4800 HPVtest (Roche Molecular Systems, Inc. Pleasanton, CA) and Abbots RealTime test (Abbots Molecular Inc. Des Plaines, IL, USA). In addition, in 2011, assays such as the Aptima test (Gen-Probe Inc, San Deigo, CA) to measure presence of viral oncoproteins E6 and E7 mRNA levels were approved.

Numerous trials and studies have shown that compared to cytology, HPV testing is more reproducible, stable over a range of ages, has higher negative predicative value and better sensitivity but specificity is lower [38-41]. When used in combination with cytology, higher sensitivities are observed [42]. Recent trials have compared HPV testing plus cytology versus cytology alone $[43,44]$. Results show that fewer high grade lesions were detected at the second round of screening than when cytology alone was used. In addition, a significantly lower number of cervical cancers or none were detected at the second round in the intervention groups of the POBOSCAM [44] and NTCC [45] trials respectively

HPV testing has been incorporated into the screening strategies in a number of countries, including the UK [6, 46,47,203-]. In particular, the technique has been used as a 'reflex 'test for triaging women who have equivocal smears or for checking samples for proof of cure (Table 3). In England, the pilot studies investigating HPV triage reported an increase in the number of women who were referred to colposcopy with a decrease in the number requiring 
repeat cytology and in the time it took to return women to routine screening. [48-50]. An economic analysis indicated that though HPV triage was expensive it was more cost effective in terms of quality and lives saved $[48,, 49]$.

In the US, HPV testing was introduced earlier in the 2000s [25,51], being used in triage of equivocal cytology only in women 30yrs and older. In younger women, transient infections may be detected by the assay, leading to undue anxiety and unnecessary excision procedures that are known to increase risk for preterm deliveries. In older women the presence of HPV is likely to indicate persistent infection. The U.S. Preventive Services Task Force [USPSTF] [46] and the ACP/ASCCP/ ASCP, American College of Pathologists/ American Society for Colposcopy and Cervical Pathology/ America Society for Clinical Pathology; guidelines for cervical screening [6] were updated earlier this year. There is good concordance for the recommendations between the two groups with both guidelines supporting longer intervals [3/5yrs] between routine testing. The main difference is that the former guidelines still recommend cytology as the primary test with use of HPV testing for triage and test of cure and for those requesting extension of the 3-year screen interval to 5years. The ACPIASCCPI ASCP recommend co-testing.

HPV testing has an additional benefit in being able to help identify women who have adenocarcinomas, which form 15\% of all cervical cancers [ ref 204]. In countries where screening programmes exist an increase in adenocarcinomas has been noted [52]. Further refinements have come in the shape of assays that separately measure the HPV16 and 18 genotypes. Data from the recent ATHENA trial shows that assessment of HPV16 or 18 separately can lead to better separation of women who, following an ASC-US or NILM result, are at the greatest risk of developing high grade lesions [53-55]. ASC-US positive women, who were HPV16+HPV18+ had nearly twice the absolute risk of CIN2+ or worse compared to women who tested positive for all high risk HPV genotypes combined (24.4\% vs $14 . \%)$. In addition, women who had negative cytology but HR-HPV positive, the data revealed that HPV16+,HPV18+ women had $11.4 \%$ absolute risk of CIN2 or worse compared to the $6.1 \%$ of women who tested positive for all HR-HPV genotypes.

Along similar lines to further stratify women who were at the highest risk of developing cancer, the first tests to measure E6/E7 mRNA are now available. Presence of HPV does not mean that malignant transformation will occur, whereas E6 and E7 expression, which is closely linked with this process is a stronger indicator of malignancy. A recent systematic review which included eight studies using the APTIMA test to triage women with a cytology result of ASC-US or LSIL showed that APTIMA is as sensitive as HC2 (54.9 vs 44.9) but has greater specificity (38.7 vs 27.8) for detecting CIN3+.[56]. The PreTECT HPV-Poofer E6/7 mRNA test (Proofer; Norchip) was been reported to have higher specificity than APTIMA (75.1\% vs $45.8 \%)$ but has lower sensitivity (79.1\%vs $94.9 \%$ ) [57].Other methodologies investigating $\mathrm{p} 16^{\mathrm{INKa}}$ expression or methylation status of a selection of tumour suppressor genes proliferation markers CDC6 and MCM5 are also being tested [58,59]. The jury is out as to which of these tests may be the preferred method for further fine tuning HPV testing.

There is now considerable interest in using HPV testing as the primary screening test for cervical cancer as it is objective, can be automated and has a high negative predicative value. Results from the extended follow-up of the ARTISTIC trial, suggest that the screening interval can be extended up to 6 years if HPV were the primary screening test as the 
negative HPV test was significantly more protective than normal cytology over three screening rounds [60]. Data emerging from recent trials in low resource settings using HPV as the primary screen have also been very promising. In a cluster-randomised controlled trial in rural India [61] of 131,746 healthy women (aged 30-59yrs) randomised to receive a single one-time screen by HPV testing or VIA or cytology or standard care (no screening), significant reductions in advanced cancers (2.5 per 1000 to 1 per 1000) and deaths (50\% mortality reduction at 7 years) were only observed in the HPV tested group compared to controls. In a separate trial marked reduction in CIN2-3 lesions were observed 36months after treatment in women who had previously been tested using HPV compared to VIA. [62].

The existing HPV technology is expensive in a low resource setting. An alternative lower cost rapid throughput test, CareHPV has recently been tested in a rural setting in China. The assay had demonstrated higher sensitivity [90\%] for identifying moderate or severe cervical disease [CIN 2+] compared either VIA (41\%) or LBC (85\%). The test requires no electricity or running water and results are available in 2.5hrs. [63]. Demonstration projects of CareHPV screening are now underway in other low-income countries (India, Uganda and Nicauragua).

All HPV tests lend themselves to self-sampling which may help overcome societal barriers to gynaecological testing. Self-sampling may be a means to reach women who have been previously unscreened [64]. A recent meta-analysis examining results of self-sampling tests versus those collected by clinical staff reported concordance between the two collection methods showing that self-collection of samples was acceptable for HPV DNA detection [65]. Self-sampling has also been tested investigated in studies in China [66] and sensitivity and specificity was in moderate agreement with those obtained with physician based collections.

In light of recent data that is currently emerging with HPV as the primary test, piloting of HPV testing with reflex cytology in the UK has recently been announced [67]. Careful consideration of the age at which this begins is required to avoid overdiagnosis and treatment in younger women who may have high levels of transient infections. Data from the POBOSCAM trial suggests testing could begin at 29years of age whereas data from the NTCC trail suggests that HPV testing should start at a later age $[44,45]$.

\section{Impact of vaccination on cervical screening}

In 2009 WHO recommended that HPV vaccines be used for prevention of cervical cancer [68]. There are two HPV vaccines against HPV 16 and 18 are Gardasil [Merck, USA] and Cervarix [GSK, UK], which are highly efficacious in preventing high grade abnormalities [69]. Very high levels of anti-HPV16 and 18 antibodies are generated, which modelling studies predict can provide protection up to 20yrs The vaccination programmes have been taken up more than 100 countries and has targeted adolescent girls, mainly aged 12-17yrs of age. Already reduction in $\mathrm{CIN} 3+$ incidence in young women $<18 \mathrm{yrs}$ have been noted. A reduction in the burden of cervical cancer especially in the developing countries and also in lower socioeconomic groups is anticipated and some reductions have already been reported [69]. However, women who have not had vaccination should continue to be screened and screening continues to be recommended in case the vaccines do not provide adequate cover against other HPV types. 


\section{Current recommendations on cervical cancer screening in low resource settings}

Modelling using data from field studies suggest that in low resource settings, if a woman is screened for cervical cancer only once in her lifetime between the ages of 30 and 40, her risk of cancer would be reduced by $25-36 \%$. If the women were screened twice (at ages 35 and 40) in their lifetime for cancer the modelling predicted their cancer risk would be reduced by $76 \%$ with HPV DNA testing and if VIA was used, by $65 \%$. The cost per life year saved using such a strategy would be less than each country's per capita gross domestic product. This strategy would be highly cost effective by the standards established by the WHO's Commission on Macroeconomics and Health [70]. The most recent guidance from the WHO recommends that all countries should have a documented cervical cancer prevention strategy that includes public education built on existing outreach programs and should define a centre or centres of excellence for the management of cervical cancer [71]. Bangladesh is one of the first among the low income countries to implement a national VIA screening programme [72].

\section{Ovarian Cancer}

Ovarian cancer [OC] continues to be the most lethal of gynaecological cancers. More than sixty percent of women diagnosed with this condition will be dead within five years of initial diagnosis in spite of cytoreductive surgery and improved therapeutic regimens. In the UK according to 2008 figures, this translates to 4,373 lives lost. In the same year 6,500 new cases will have been diagnosed [ ref 205]. Globally, ovarian cancer accounts for $3.7 \%$ of all female cancers worldwide, with an estimated 225,000 new cases diagnosed and 140,000 deaths occurring in 2008 [201 ]. Women in the industrialised nations are almost twice as likely develop ovarian cancer [ASR 9.4 per 100,000] compared to the developing nations [ASR 5.0 per 100,000] [1]. The highest ovarian cancer incidence rates are recorded in Europe and the Northern America, and the lowest rates in Africa and parts of Asia.

Although there have been recent attempts to raise awareness of the symptoms of the disease [206,207], available mortality rates indicate that women are continuing to be diagnosed with advanced disease which has spread beyond the ovary. When the cancer is diagnosed at an early stage (Stage I), prognosis is much better; and more than $90 \%$ of women are reported to survive for 5 years or more [208].

At present there are no national screening programmes for ovarian cancer akin to those in cervical cancer. Large trials have been instigated to investigate the strategies best suited to detect preclinical disease in women who are most at risk. These fall into two groups: (1) General population - Women $\geq 50$ years with no significant family history [this includes none or one relative with ovarian cancer] (2) High-risk population - Women $\geq 35$ belonging to familial breast and/or ovarian cancer families. First-degree female relatives of cancer sufferers in such families have a lifetime risk of developing ovarian cancer of approximately $>10 \%$. [73] Germline mutations in the genes, BRCA1 and BRCA2, account for a high proportion of this risk. Mutations in BRCA1 are associated with a lifetime risk of ovarian cancer of about $40-50 \%$ and mutations in BRCA2 with $11-26 \%$. The OC risk for women with Lynch syndrome is approximately $10 \%$ [73]. 


\section{Screening methodologies}

The techniques which have been used alone, sequentially or in combination to screen for OC have been adopted from routine clinical practice. These include pelvic examination, ultrasonography and assessment of serum CA125 levels. Because of the low prevalence of ovarian cancer in the population the challenge has been to achieve sufficient specificity (>99.6\% for $10 \%$ PPV) [74] to avoid high false positives rates as cancer diagnosis can only be confirmed following surgery and histological examination of the removed adnexa. Pelvic examination has not the sensitivity nor specificity required by early detection of ovarian cancer and has largely been discarded for this purpose.

\section{Ultrasound}

The availability of real-time ultrasonography for gynaecological examinations led to the suggestion that ultrasound examination of ovarian size and morphology could be used to screen for ovarian cancer [75, 76]. It has been used both as a primary and second line screening test. Transvaginal ultrasound (TVS) is the preferred method for visualising ovaries compared to the transabdominal approach because of better resolution. TVS is both acceptable to the women and has low inter-observer variation [77, 78]. Because of the subjective nature of the technique, a key concern has been to provide a framework for distinguishing benign adnexal masses from those that are malignant to avoid the need for excessive surgery. Published data show that some features of the ovarian morphology (papillary projections, complex ovarian cysts with wall abnormalities or solid areas] are strongly associated with the presence of malignancy compared to others (septal thickness, unilocular ovarian cysts $<10 \mathrm{~cm}$ in diameter and inclusions cysts) and are the basis of various algorithms used for differential diagnosis of a pelvic mass $[79,80]$. In the absence of data on ultrasound appearance of preclinical lesions, most ovarian cancer screening trials have defined all ovarian cysts with complex morphology as abnormal and used repeat scans and clinical evaluation to manage abnormal findings. The major trial that has reported prospective use of a morphology score is the University of Kentucky Ovarian Cancer Screening Trial [81]. In the course of the trial $55 \%$ of all the abnormalities detected by screening were ovarian cysts less than $10 \mathrm{~cm}$ in diameter or septated cysts without solid areas or papillary projections and none progressed to malignancy. The original tumour profiling index was modified to return these women to annual screening. As a result of these modifications the positive predictive value (PPV) of ultrasound in this trial rose from $14.1 \%$ to $20.2 \%[81]$.

Postmenopausal ovaries can be difficult to visualise, especially with diminution of these organs with age. In UKCTOCS, quality assurance programmes were established for ultrasound scanning in an attempt to ensure that scanning quality was as uniform as possible across all sites. All ultrasonographers were required to undertake an initial program of training for screening postmenopausal ovaries and followed by a process of examination for accreditation which then had to be renewed bi-yearly. The impact of introducing the accreditation programme into UKCTOCS is currently under analysis.

\section{CA125}

CA125 [MUC16] is a high molecular weight [average 2.5-5 MDa], Type 1 transmembrane glycoprotein, which is overexpressed in ovarian cancer [82]. It was first described by Bast et 
al in 1981 through its binding with murine monoclonal antibody OC125 [83]. CA125 comprises a heavily glycosylated extracellular domain, an intra-membranous domain and a short cytoplasmic tail [82]. Shedding of the extracellular domain is thought to occur in response to intracellular signalling. The normal function of CA125 is not known but the first direct evidence for a functional role in ovarian cancer cells has recently been presented [82]. The mucin modulates tumor cell growth, cell motility, invasive and metastatic properties and tumorigenesis. Tumour growth may also be influenced through the inhibition of natural killer cells [84]. CA125 is not unique to ovarian cancer, with increased levels being observed in non-gynaecological malignancies, infections, inflammatory disease as well as being found in benign conditions such as menstruation, pregnancy and endometriosis [73].

Serum CA125 is assessed through an immunoassay. The first of these used the OC125 antibody for both capture and detection. This assay has been superceded by the widely used second generation heterologous CA125-II assays, that include a second monoclonal antibody M11 which recognises a different antigenic domain from OC125 [85]. A variety of assays are available, many of which are automated. However, differences in reagent specificities and assay design can lead to variation in values obtained, and means that the results may not be interchangeable and a changeover in assay requires parallel testing.

A CA125 level of $35 \mathrm{IU} / \mathrm{ml}$ is usually accepted as the upper limit of normal. [86]. However, it has been suggested that cut-offs based on menopausal status maybe be more appropriate in screening asymptomatic women. A cut-off of $20 \mathrm{IU} / \mathrm{mL}$ has been suggested following menopause [87]. In a more recent analysis cut offs of approximately $50 \mathrm{IU} / \mathrm{ml}$ in premenopausal women, $40 \mathrm{IU} / \mathrm{ml}$ for premenopausal women on oral contraceptives and 35 $\mathrm{IU} / \mathrm{ml}$ for postmenopausal women have been suggested [88]. Approximately $85 \%$ of patients with epithelial ovarian cancer have CA125 levels of $>35 \mathrm{U} / \mathrm{ml}$, with elevated levels found in $50 \%$ of patients with Stage I disease and over 90\% of patients with Stage II-IV disease [89]. Up to $20 \%$ of cancers, mainly mucinous and borderline do not express significant levels of CA125.

The discovery that CA125 was raised 5 years in advance of ovarian cancer [90] led to it being investigated as a screening test. CA125 by itself does not perform well as a screening test. It has low sensitivity and specificity. However, when used in multimodal testing these parameters improve. Sequential CA125 measurements and pelvic ultrasound in a trial of 22,000 women, achieved a specificity of $99.9 \%$ and PPV of $26.8 \%$ for detecting ovarian and fallopian tube cancer [91] requiring four operations to detect one case of ovarian cancer. To improve performance, serial CA125 has been incorporated into algorithms to predict a women's risk of ovarian cancer. In women with ovarian cancer CA125 levels tend to increase over time compared to other conditions such as benign gynecological disease where CA125 may be high but tend to remain constant [92]. Observing these patterns of change, Skates and colleagues developed a computerised Bayesian algorithm, Risk of Ovarian Cancer (ROC), using serum CA125 measurements [93]. Using an individual's agespecific incidence of ovarian cancer and her CA125 profile the algorithm generates a risk estimate (ROC value) based on comparing her pattern to those observed in women known to have been diagnosed with ovarian cancer. The greater the correlation of the test pattern to established CA125 profiles in OC, the greater the ROC value and therefore the risk of OC [94]. Based on this estimation, women are triaged into low, intermediate and elevated-risk groups. The women at intermediate risk have a repeat CA125. Those that have an elevated 
risk are referred for a repeat CA125 and transvaginal scanning. If either result is abnormal, the women are referred for clinical assessment with a gynaecological oncologist with a view to surgery.

The ROC algorithm was first tested in a randomised controlled trial involving 13,582 postmenopausal women. It showed a high specificity (99.8\%; $95 \% \mathrm{Cl} 99.7$ to 99.9$)$ and PPV (19\%; 95\% Cl 4.1 to 45.6 ) for primary invasive epithelial ovarian cancer [95]. It is currently being tested in trials in both high and low risk trials in the USA and UK [88,96, 97,209,].

Combining CA125 with other biomarkers has been suggested as a means of improving sensitivity and specificity for detecting ovarian cancer early. A number of candidates, including prolactin, transthyretin or apolipoprotein A1, human epididymis protein 4 (HE4), CA72-4, and CA15-3, have been identified and tested [98,99]. However, none of combinations of markers have improved on CA125. One biomarker however, which has shown promise is HE4, especially in early disease. This is elevated in epithelial ovarian cancers (EOCs) and not in benign gynaecological conditions and maybe helpful in cancers where CA125 is not expressed [100]. Its use as a second biomarker in a multimodal screening strategy is being investigated in the Novel Markers Trial. [210]. The Risk of Ovarian Malignancy Algorithm (ROMA), which uses HE4 alongside CA125 has recently been approved for differential diagnosis of patients presenting with adnexal mass and is not a screening test [ref 211].

\section{Screening trials}

\section{General population}

Initial evidence of improved survival with screening was provided by a randomised trial in 21,935 women which showed higher median survival [72.9 months] in women with ovarian cancers detected in the screened arm compared to controls [41.8 months] who did not undergoing screening [101]. Subsequently, a number of large prospective screening trials have been conducted using CA125 alone, ultrasound alone or both in combination $[81,97,102,103]$. There are three randomised controlled trials and one population controlled trial. In the former group, the Shizuoka Cohort Study on Ovarian Cancer Screening [SCSOCS] trial [102] showed no significant difference in the number of cancers detected in the screened arm [ $n=41,688$ ] compared to control [ $n=40,799]$ in low risk women using a combination of CA125 and TVS. Although there were more early stage cancers in the screened arm [63\%] compared to the control [38\%], the difference was not significant. The mortality rates from the Japanese trial are yet to be reported. The Prostate, Lung, Colorectal and Ovarian [PLCO] Cancer Screening Trial [103], conducted in the US is the only large randomised trial to report mortality data, including both primary fallopian tube and peritoneal cancers. The trial recruited 78,216 postmenopausal women. Participants were screened using serum CA125, and transvaginal ultrasonography for 3 years, followed by CA125 alone for a further 2 years in those women who were still eligible. The women were followed up for a median of 12.4 years. Ovarian cancer was diagnosed in 212 women in the screened group and 176 in control women. Stage distribution was similar across the groups with most cancers being stage III/IV. Although the trial had adequate power, extensive outcome review and minimal contamination, no differences in ovarian cancer deaths or survival were observed in screened women compared to controls. In addition, 15\% of women undergoing 
surgery for benign pathology experienced at least one serious complication. The lack of effect may have been due to a number of reasons [104,105], and this includes the absence of a protocol driven management process, with the follow-up of abnormal results being left to the discretion of the women's treating physician which may have resulted in delayed action. There was also no mention of a quality assurance programme to ensure delivery of high quality ultrasound. In addition, there was a dilution of screening effect, with $40.6 \%$ cancers in the study arm being diagnosed after screening ended [4-6 years screening and median follow up of 12.4 years], with those diagnosed more than 2 years after screening unlikely to have been affected by screening. The PLCO and the Japanese Cohort Study both used a single CA125 assessment with a $35 \mathrm{IU} / \mathrm{ml}$ cut off. In an attempt to see if implementation of ROCA would have made a difference to the results of the ovarian arm of the PLCO, Pinsky et al [106] recently undertook modelling studies to test this using updated data from the PLCO trial. Although the model suggested that 43 cancers could have been detected earlier with ROCA, almost a median of a year in advance for fatal cases, a significant. mortality benefit would not have been observed.

In United Kingdom Collaborative Trial of Ovarian Cancer Screening [UKCTOCS] [97] 202,638 low risk women were randomised to one of three arms (ultrasound (U), multimodal $(\mathrm{M})$, control (C)) in a ratio of 1:1:2. Women in the $U$ arm underwent annual TVS and, those in the $\mathrm{M}$ group had a blood test for serum CA125 assay. The CA125 was interpreted using the ROC algorithm. Abnormalities were triaged according to well defined protocols to either repeat testing and/ or further investigations. In the prevalence screen $0.2 \%$ women from the MMS group and $1.8 \%$ from the $U$ group underwent surgery. A total of 87 primary ovarian and tubal cancers, including 28 borderline tumours were detected. with $48.3 \%$ (95\% Cl 35.0$61.8)$ of the invasive cancers stage I/II. There was no significant difference in the stage distribution between the groups. The sensitivity, specificity, and positive-predictive values for primary invasive epithelial ovarian and tubal cancers were $89.5 \%, 99.8 \%$, and $35.1 \%$ for $\mathrm{M}$ group, and $75.0 \%, 98.2 \%$, and $2.8 \%$ for $U$ group respectively. Although the prevalence data look promising, any mortality benefit can only be assessed when results of the incidence screening are reported in 2015. UKCTOCS is still ongoing; screening in UKCTOCS completed in Dec 2011 and the women are currently in the follow-up phase. Results of this trial will inform the decision to have (or not) an ovarian cancer screening programme in the UK. Parallel studies to this trial are examining the health economics and also the psychosocial aspects of screening [107].

The University of Kentucky Ovarian Cancer Screening Trial [81], is a population controlled trial, which is a single arm trial using ultrasound as the primary screening tool, with morphology profiling. The screening algorithm used which has allowed for a higher specificity [98.8\%] and PPV [20.2\%] than thought possible for this technique [108]. The sensitivity for primary invasive epithelial was higher [79.7\%] than that for ultrasound scanning in PLCO [67.4\%]. In UKCTOCS prevalence screening sensitivity for ultrasound was $75 \%$. These authors reported that annual ultrasound screening of asymptomatic women resulted in increased detection of early ovarian cancer as well as a significant increase in the 5 year survival rate compared to women diagnosed clinically. Forty-seven invasive epithelial ovarian cancers and 15 epithelial ovarian tumours of low malignant potential were detected during 895,032 woman years of screening. $70 \%$ of the cancers detected were Stage I and II. Whilst data from the Kentucky trial offer hope, these findings 
may reflect a combination of a healthy volunteer effect and lead time of screen detection. Reduction of mortality in a screened population in a randomised control trial is sorely needed for screening to have an impact on OC outcomes.

\section{High-risk women}

Annual screening in high risk women with a family history of ovarian/early breast cancer or mutations in genes such as BRCA1/2 is not regarded as efficacious [109]. Results from the recently reported Phase-1 of the UK Familial Ovarian Cancer Screening Study [UK FOCSS] indicated a sensitivity of $81.3-87.5 \%$, PPV of $25.5 \%$ and NPV of $99.9 \%$ with annual screening. The findings indicated that screening more frequently than annually with prompt surgical interventionmay offer a better chance for detecting early stage disease [110]. Cancers in these women are often high grade serous EOCs which progress rapidly and a shorter screening interval might be beneficial [111]. This is currently being tested in Phase 2 of the UKFOCSS, which is a prospective single arm screening study involving 5700 women [209]. Screening is based on four monthly CA125 testing, interpreted using the ROC algorithm and an annual TVS. The trial will report in 2013. Reports of screening in this population are also anticipated in 2013 from the US trials, the GOG-199 study and the US Cancer Genetics Network trial [112]. In the absence of a validated screening programme, women in the UK NHS who are at increased risk of familial ovarian cancer are counselled for genetic testing and offered the option of undergoing risk reducing surgery once they have completed their family.

\section{Other early detection strategies}

For decades ovarian cancer has been considered a disease with minimal symptoms until advanced stage. In 2000, a large retrospective survey conducted by Goff and colleagues [113] showed that up to $95 \%$ of women experienced symptoms between 3-6 months prior to diagnosis The most common symptoms were abdominal (77\%), gastrointestinal (70\%), pain $(58 \%)$, constitutional [(0\%), urinary (34\%), and pelvic (26\%) with gynaecologic symptoms being the least common. Interestingly, symptoms were not related to stage and even in women who were diagnosed with early stage disease, $89 \%$ reported symptoms. The frequency and severity of the symptoms was reported to be higher in women with ovarian cancer than in women with other conditions [114,115]. However, in many such studies the positive predictive value was low and retrospective data was used for analysis. Nonetheless, it was generally agreed that awareness of OC symptoms in women and primary care physicians may help to reduce the time to specialist referral and/or investigation. To this end consensus statements were issued by the Gynecologic Cancer Foundation, the Society of Gynecologic Oncologists, and the American Cancer Society in the US and also in the UK, a consensus statement and information leaflets were released by cancer charities and Department of Health listing the most frequently observed symptoms associated with ovarian cancer [81, 82, 212,213]. In the UK The National Institute for Health and Clinical Excellence [NICE] recently recommended that a CA125 test should be offered to women with symptoms suggestive of ovarian cancer, with aim of obtaining an earlier diagnosis [214]. Women with higher levels of the marker would then be offered an ultrasound scan while those with persistent symptoms but normal levels would be offered repeat testing. There has been 
concern from the medical community that these guidelines were not based on prospective studies and the implications of wide spread CA125 testing had not been assessed $[116,117]$.

A symptom index developed by Goff and colleagues [118] has been recently tested in combination with CA125 and HE4 in a prospective case - control study involving 74 women with OC and 137 healthy women controls. The SI alone had sensitivity of $64 \%$ with specificity of $88 \%$. A rule based on any two of the three tests being positive had a sensitivity of $84 \%$ with a specificity of $98.5 \%$ [119], with a positive rate of $1.5 \%$. The authors suggest that the use of such an instrument as a first line test, may be helpful in selecting women for further diagnostic testing [118]. Further independent testing of this approach is warranted. Data relating to symptoms in women enrolled into UKCTOCS are been collected prospectively. This is currently being analysed [Menon, personal communication].

More recently, results from a prospective pilot study using a symptoms based approach has been published. Women aged 50yrs and over who presented with symptoms of ovarian cancer were offered CA125 testing and TVS [120]. In 1455 women assessed, 22 gynaecological cancers were diagnosed, 11 were invasive epithelial ovarian cancer, nine of which were high grade serous carcinoma. Five were associated with only slightly raised CA125 concentrations and minimal or no ovarian abnormalities on TVS. $73 \%$ tumours were completely resectable in study patients, compared to $44 \%$ in clinic patients. Though these observations are promising, a larger ideally randomised controlled trial is needed to confirm these data and ensure that the findings are not due to a 'healthy volunteer effect' [121].

\section{Shifting sands}

There is no evidence at present that screening for ovarian cancer has a mortality benefit and the latest USPSTF recommendation reflects this [122]. OC screening instead may cause harm. However, mortality data from two randomised trials, SCSOCS and UKCTOCS are still awaited and these will provide valuable information for future recommendations. In parallel, recent mathematical modelling studies have suggested that current methodologies might be incapable of detecting ovarian cancers at an earlier stage or at most have a modest effect on mortality rates $[123,124]$. Unpublished data from our group suggests that in some cases the ROC may facilitate detection of small volume disease [Menon 2012].

Also emerging at this time, is increasing evidence that the origins of ovarian cancers may not be rooted in ovary itself but in other tissues [125]. Most high grade serous EOCs in BRCA1/2 mutation carriers and also in about $50-60 \%$ of women with sporadic ovarian cancers are thought to initiate in the fimbriae of the fallopian tube [126-128]. With ultrasound scanning focussed only on the ovarian tissue, it is understandable why earlier high grade serous cancers may be missed.. New technologies such as autofluorescence for detection of these cancers are now being investigated by a Canadian group [129].

There is increasing recognition that ovarian cancer is not one disease but several multifaceted entities. Five main histological subtypes of ovarian cancer [serous, mucinous, clear cell, endometrioid and transitional cell/Brenner tumors] have been identified, which differ with respect to genetic mutations, precursor lesions, stage of presentation and responsiveness to chemotherapy [130-132]. A recent proposed model for categorising these different cancers into two main types, (Type I and Type II), has recently been proposed by 
Kurman and Shih $[133,134]$ based on tumour behaviour and pathogenic pathways. Type I cancers include low-grade serous carcinoma, low-grade endometrioid carcinoma, mucinous carcinoma, Brenners tumours and a subset of clear cell carcinomas. These cancers are genetically stable and rarely express TP53.They are slow growing, have defined precursor lesions and are generally detected at an early stage. Type II tumours on the other hand are genetically unstable, have high level of TP53 mutations and are aggressive, rapidly growing carcinomas which are detected at an advanced stage. The high mortality rates in ovarian cancer arise mainly from these latter type of cancers, which make up $75 \%$ of all epithelial ovarian cancers. Type II cancers include the high-grade serous, high-grade endometrioid, malignant mixed mesodermal tumours and undifferentiated carcinomas. High grade serous ovarian cancers make up the large proportion of type II cancers. Although the dualistic model is a good one, there are concerns that it does not cater for differences between the histotypes in Type I group. Given the recent insights into disease aetiology and heterogeneity of $\mathrm{OC}$, there is increasing need for novel detection methods that are histotypespecific. There are concerns that current strategies such as ultrasound scanning and serum CA125 may be biased towards detection of Type I and Type II tumours respectively.

A very recent publication by Kinde et al [2013] [135] has ignited much interest. These authors described the use of a sensitive massively parallel sequencing method for detecting gynaecological cancer associated somatic mutations in LBC samples from 24 endometrial cancers and 22 ovarian cancers. Their technique detected $100 \%$ of endometrial cancers and $41 \%$ of ovarian cancers offering the possibility that a single test [LBC] could be used for detecting the presence of multiple gynaecological cancers. However, this requires further confirmation, validation and research before use in clinical practice.

\section{Uterine cancer}

Like ovarian cancer, uterine cancer is more common in the industrialised nations than in the developing world [215]. It is the leading gynaecological cancer in North America (ASR 16.4 per 100,000), Europe (ASR 12.3), Australia/New Zealand (ASR 11.5). The lowest rates are observed in Africa (ASR 2.6 per 100,000). In the UK 7,468 women were diagnosed with uterine cancers in 2008 and 1,554 died of the disease. 93\% of uterine cancer cases are diagnosed in women aged 50 years and over. Incidence rates peak in the early seventies at 83 per 100,000 and begins to decline from 75 years onwards [215]. The majority of uterine cancers are endometrial with less than $4 \%$ being uterine sarcomas. This review will focus on endometrial cancer.

Endometrial cancer is becoming a concern as its incidence has risen in recent years. In America which has the highest incidence of this cancer, a 21\% increase has been observed since 2008 and the mortality from the condition has increased by $8 \%$ during the same time [136]. In the UK the incidence of endometrial cancer has risen by nearly $20 \%$ [216] in the last decade and mortality rates have increased from 3.1 to 3.7 per 100,000 since the late 1990s [216]. A recent assessment of data from an English cancer registry showed that the greatest increases have been observed in the 60-79 years age group [137]. The increase in endometrial cancer is thought to be related to the rise in obesity, women having fewer children and the aging population [138]. 
Other risk factors include unopposed oestrogen stimulation, late menopause, diabetes mellitus, nulliparity, feminising ovarian tumours, polycystic ovarian syndrome, use of tamoxifen and familial disposition. The key driver appears to be unopposed oestrogen, which after menopause arises from aromatisation of androstenedione to oestrone in the adipose tissue. The risk for endometrial cancer is higher in obese women [139, 140], with this being reported as six times higher in women with a $\mathrm{BMI} \geq 40$ compared lean women in one report [139]. The risk of death in women with endometrial cancer who have a BMI $\geq 40$ is also increased [RR 6.25] [136,140].

Two types of endometrial cancers have been described [141]. Type I (80\%) cancers occur in younger, obese, or perimenopausal women and are associated with oestrogen. They are usually low-grade, histologically characterised as endometroid and have a good prognosis. They arise from hyperplastic changes with a definable precursor lesion, atypical endometrial hyperplasia $[\mathrm{AEH}]$. The thickened endometrium is detectable by ultrasound. Ten percent of endometrial cancers are Type II cancers, which occur in older women and express neither estrogen nor progesterone receptors. Type II cancers are high grade malignancies, with a serous or clear cell histology, which resemble aggressive serous or clear cell cancers seen in the ovary or cervix. Prior radiotherapy may be a risk factor for development of these cancers [136]. Type II cancers appear as focal thickening in a thin endometrium and can be missed on ultrasonography. In the US these types of cancers are more frequently seen in African-American women and have a poor outcome [136, 142]. Data from a West Midlands cancer registry showed that [137] that whilst survival rates remain stable for Type I, 5 year rates in Type II cancers have fallen significantly from $55.1 \%$ to $40.9 \%[(P<0.001)$.

A family history should be ascertained in all endometrial cancer cases as $10 \%$ are hereditary [136]. Such cancers arise as part of the Lynch syndrome [LS], also known as hereditary nonpolyposis colorectal cancer [HPNCC] $[143,144]$. Both Type I or Type II cancers are represented in LS. Families are identified based on the Amsterdam II [145] or on the revised Bethseda Criteria [146]. LS is an autosomal dominant syndrome caused by germline mutations in any one of the DNA mismatch repair [MMR] genes: mutL homolog 1 (MLH1), mutS homolog 2 (MSH2), postmeiotic segregation increased 1 (PMS1), post-meiotic segregation increased 2 (PMS2) and mutS homolog 6 (MSH6) [136]. Proteins encoded by the MMR genes are critical to the repair of DNA sequence mismatch. Loss of MMR function leads to DNA replication errors in the simple short-tandem DNA repeat sequences of 1 to 6 bases, called microsatellites. As a result these microsatellites lengthen or shorten, a process known as microsatellite instability $[136,144]$. Women who have these mutations are at risk of developing colorectal, ovarian and endometrial cancer. More recently there is evidence that the range of cancers that can occur in these families is greater than originally believed $[147,148]$. The lifetime risk of endometrial cancer is estimated to be between $30-70 \%$ and dependent on the type of mutation [149]. Other studies suggest a lower risk of $14 \%-30 \%$ when controlled for ascertainment bias [150]. Using the genotype restricted likelihood (GRL) method accounting for this bias, a recent French study reported cumulative risks for endometrial cancer as 54\% (95\% Cl, 20\%-80\%), 21\% (95\% Cl, 8\%-77\%), and $16 \%(95 \% \mathrm{Cl}$, $8 \%-32 \%)$ for MLH1, MSH2 and MSH6 respectively by 70yrs of age [151]. By age 40 years the estimated cumulative risks did not exceed $2 \%(95 \% \mathrm{Cl}, 0 \%-7 \%)$ for this cancer for the genes tested, suggesting that prophylactic surgery in these women could be considered after this age. 


\section{Screening for Endometrial Cancer}

Screening is not advocated for endometrial cancer in the low risk population as $95 \%$ of the women become symptomatic whilst the cancer is still at an early stage and curable. The commonest presentation is abnormal vaginal bleeding and approximately $10 \%$ of women with postmenopausal bleeding [PMB] are diagnosed with endometrial cancer. $72 \%$ of these cancers are stage I, 12\%are stage II, $13 \%$ are stage III, and $3 \%$ are stage IV [136].

The overall five year survival is $77 \%$ [217]. As result only a few studies [138, 152-156] have assessed the benefits of screening in this population. However, as the population grows not only in number but also in girth and lives longer, the question arises whether women at risk of developing endometrial cancer could be identified and lesions detected earlier. The presence of a precursor lesion, $\mathrm{AEH}$, also raises the possibility of impacting on incidence as in cervical cancer. A nested case-control study of endometrial cancer and AEH was undertaken using data from 37,038 women who underwent TVS in the ultrasound arm of UKCTOCS [138]. An endometrial thickness (ET) of $10 \mathrm{~mm}$, had a sensitivity of $54 \cdot 1 \%$ (95\% Cl45.3-62.8) and would lead to approximately 17 diagnostic interventions per case detected. A lower ET threshold of $\geq 5 \mathrm{~mm}$ would increase sensitivity (80.5\% (95\% Cl72.786.8)) but result in 56 diagnostic procedures per case. A logistic regression model was developed incorporating epidemiological data [of the use of the oral contraceptive pill, age at menarche, number of pregnancies, weight, age, and history of cancer] to stratify women according to risk of endometrial cancer. Based on the data available for women who represented the top $25 \%$ of an 'at high risk' population, cut-off of an endometrial thickness of $6.75 \mathrm{~mm}$ achieved sensitivity of $84.3 \%$ (95\% Cl71.4-93.0) and specificity of $89.9 \%$ (95\% Cl89.3-90.5) for endometrial cancer. 39.5\% of known endometrial cancer or AEH cases were located with this top quartile of women. An approach such as this may help to triage women with a complement of risk factors for future screening investigations.

At present regular medical surveillance is restricted to those women who are at risk of LS, and wish to delay or avoid preventative surgery. Endometrial cancer in LS women is often diagnosed in their forties and fifties, some 10-20 years earlier that in low risk women. Screening is recommended from the age of 35 using TVS and endometrial sampling (with or without hysteroscopy) [176/156,177/157].An endometrial thickness of 3-5mm on TVS triggers further investigation.

Pipelle endometrial biopsy is a well-established method for endometrial sampling that can be performed as an outpatient procedure. However, it has a tissue yield and procedure failure rate of around $10 \%$ [178/158] and inadequate samples are more common in the postmenopausal age group. Cancers have been reported to be missed on pipelle alone. A large meta-analysis reported a $99 \%$ sensitivity of pipelle to diagnose endometrial cancer and $81 \%$ for hyperplasia in postmenopausal women and a sensitivity of $91 \%$ in premenopausal women, while maintaining a specificity of $>98 \%$.[178/158]

Hysteroscopy directed endometrial sampling is the accepted gold-standard and is now routinely performed as an outpatient procedure. No significant difference in pain scores has been reported between approaches using either hysteroscopy or endometrial sampling 
alone [159]. In addition, initial reports did not find any psychological morbidity associated with hysteroscopy-based endometrial screening in LS [160]. Hysteroscopy can detect pathology which may be missed by both ultrasound and pipelle $[161,162]$. Hysteroscopy has been found to detect premalignant lesions in two asymptomatic cases in one surveillance study [161]. No screen detected cancers were reported in asymptomatic high-risk women undergoing annual hysteroscopy in two earlier reported series [154, 163] Out-patient hysteroscopy failure rates of $8 \%$ and $11 \%$ were found in these two series.

Results of a more recent prospective observational cohort study of 41 LS women attending a tertiary high-risk familial gynaecological cancer clinic have been reported [164]. These data show that showed annual outpatient hysteroscopy and endometrial sampling (OHES) is acceptable to the women and has high diagnostic accuracy for endometrial cancer. 4 cases of endometrial cancer/ atypical endometrial hyperplasia were detected using this approach compared to two detected by TVS. OHES had similar specificity of $89.8 \%(\mathrm{Cl} 79.2,96.2 \%)$, but higher positive likelihood ratio (PLR) $9.8(\mathrm{Cl} 4.6,21)$ and lower negative likelihood ratio (NLR) (0) compared to TVS: specificity $84.75 \%$ (Cl 73, $92.8 \%$ ), PLR 3.28 (Cl 1.04, 10.35) and NLR $0.59(\mathrm{Cl} 0.22,1.58)$. The results of the study reinforce the current recommendation that endometrial sampling is crucial when screening these women but suggest the need for larger studies.

\section{Expert Commentary}

This is an exciting time in gynaecological oncology with our understanding of disease pathogenesis increasing in leaps and bounds. This is set to shape the future landscape for screening in female cancers. In cervical cancer it is likely that HPV testing will replace cytology as the primary tool for screening in both high and low income settings. In addition tests specific for assessing malignant potential of precancerous lesions, for example E6 and E7 oncoproteins expression, will help tailor management protocols. HPV vaccination programs have been implemented in a number of countries and impact on cervical cancer screening programmes will only be known in the next decade or so.

In ovarian cancer, the most lethal of all gynaecological malignancies, there continues to be no evidence that screening can save lives. Mortality data from the largest randomised controlled trial [UKCTOCS] will be available in 2015. Meanwhile advances in molecular and genetic profiling has revealed the extent of epithelial OC heterogeneity, highlighting the need to refine screening strategies to take into account detection of the individual histological types. Most intriguing of all is the increasing evidence for the non- ovarian origins of OC, especially of high grade serous malignancies which exhibit an aggressive, fast progressing phenotype.

Endometrial cancer is increasing at an alarming rate and thought to be linked in part to the obesity epidemic. Serious consideration should be given to limit this increase. Improved risk stratification strategies in the general population with targeted screening within a defined higher risk sub-group may further improve screening performance. 


\section{Five year view}

The gynaecology oncology community is on the cusp of changes which will alter management of common gynaecological cancers. The approach to screening in the general population will be more focussed with improved risk stratification at its core. Driving this will be the rapid growth in technology and access to biobanked samples that predate cancer diagnosis that will help unveil additional molecular and genetic pathways of these cancers. Secondly, as the world population grows, and places additional burden on healthcare resources, there is need to target those at greatest risk.

The incidence of cervical cancer will change as the global pool of vaccinated women enlarges and more women have access to screening. Primary HPV testing with cytology triage is the most likely future strategy for cervical cancer screening over the next five years. Molecular testing will continue to focus on genotypes HPV 16, 18 and HPV45 and associated markers of malignant transformation. Low cost assays are already being tested in developing countries where the disease burden is the greatest. Structured screening programmes will be implemented in many countries which do not as yet have one. The high negative predicator value of the HPV testing means that longer screening intervals are feasible and in low resource countries even one or two rounds of screening will significantly lower the risk of cervical cancer. The key to reduction will require policy makers and healthcare providers to ensure that coverage is maximal, there is quality assurance of the screening programmes and appropriate treatment facilities.

The future of ovarian cancer screening in the UK will be decided once the two largest prospective screening trials, UKFOCSS in high-risk women and UKCTOCS in low-risk women, report in 2013 and 2015 respectively. The trial designs in these studies differ from the earlier trials that have already reported negative results and the outcomes are awaited beyond the UK. Meantime, there will be a significant growth in studies trying to unravel the heterogeneity of ovarian cancer so that more finely tuned early detection modalities may be adopted. There is a significant effort underway already to identify humoral or tissue based biomarkers of preclinical disease and to develop newer assays for their detection. Predictive modelling using genetic and epidemiological and clinical data to define risk will assist in this triage.

The increase in endometrial cancer is alarming. The control of this cancer is in part related to the wider efforts in the management of the obesity pandemic. A high level UN meeting in 2011 has already called for action in tackling the negative impact of unhealthy lifestyles on the incidences of cancers and other non-communicable diseases such as CVD and diabetes. Raising awareness of the risk factors of this disease is warranted. Models for identifying women at increased risk of developing sporadic cancer are being developed and will help identify a higher risk group who could benefit from screening for this disease. Prospective trials which evaluate mortality and quality of life outcomes will be needed to validate this approach. 


\section{Key issues}

Gynaecological cancers are a significant cause of morbidity and mortality in women worldwide.

\section{Cervical cancer}

- Cervical cancer is preventable as the causative agent HR-HPV is known and precancerous lesions are well characterised and detectable on screening

- A wide variety of screening tests to suit varying needs have been developed and evaluated. The latest tests undergoing evaluation include HPV E6/E7 mRNA and cheaper, rapid throughput fields test such as careHPV.

- Primary HPV testing has emerged as the most likely future strategy

- A mortality benefit has been shown in large randomised controlled trials following even a single round of screening

- In low to middle income countries where the bulk of the disease is observed, the urgent need is to implement cervical screening programmes using cost effective strategies such as visual inspection and to introduce quality assurance where such programmes already exist.

- In developing countries, where such programmes have been a success, the need is improve coverage especially in younger women and to fine tune screening strategies to identify women most at risk whilst minimising overdiagnosis and over treatment. Recent guidelines will assist in this effort.

- Vaccination programmes have begun alongside screening in over 100 countries

\section{Ovarian cancer}

- The most lethal of al gynaecological cancers. More than $60 \%$ of women with ovarian cancer will die within 5 years of diagnosis.

- Utility of screening uncertain at present. One large randomised controlled trial has reported no mortality benefit while results of the second larger trial with a different screening strategy are awaited

- Increasing understanding of the heterogeneity and natural history of ovarian cancer will allow development of novel screening approaches.

- The future focus needs to be to develop assays and optimise strategies for detection of low volume primary invasive epithelial ovarian cancer

\section{Endometrial cancer}

- Rates of endometrial cancer are escalating. Approximately $50 \%$ are related to obesity, which is also on the rise. Other factors are decreasing parity and age. 
- Screening not available currently because women are usually symptomatic and diagnosed in early stages when prognosis is good.

- Currently available strategy using TVS has high false positive rates and needs further optimising

- There is need to develop risk stratification methods to identify women in the general population at increased risk

- Screening strategy for high risk Lynch Syndrome women needs to be optimised 


\section{References}

1. Jemal A, Bray F, Center MM, Ferlay J, Ward E, Forman D. Global cancer statistics. CA Cancer J Clin. 61(2):69-90. (2011) Epub 2011 Feb 4. Erratumin: CA Cancer J Clin. 61(2):134. (2011)

2. Castle, P. E. More evidence supporting human papillomavirus testing. Nat. Rev. Clin. Oncol. 9, 131-132 (2012).

3. Mathew A, George PS. Trends in incidence and mortality rates of squamous cell carcinoma and adenocarcinoma of cervix world worldwide. Asian Pac. J. Cancer Prev 10, 645-650 (2009).

4. Glick SB, Clarke AR, Blanchard A, Whitaker AK, Cervical cancer screening, diagnosis and treatment interventions for racial and ethnic minorities: a systematic review. J Gen Intern Med. 27(8),1016-32 (2012)

5. Saslow D, Solomon D, Lawson HW et al. ACS-ASCCP-ASCP Cervical Cancer Guideline Committee. American Cancer Society, American Society for Colposcopy and Cervical Pathology, and American Society for Clinical Pathology Screening Guidelines for the Prevention and Early Detection of Cervical Cancer. CA Cancer J Clin. 62(3),147-72 (2012).

6. Wilson JMG, Junger G. Principles and practice of screening for disease. WHO Chronicle. Geneva. World Health Organisation 22 (11), 473 Public Health Papers, \#34. (1968).

7. Wright TC, Ronnett BM, Kurman RJ, Ferenczy A. Precancerous lesions of the cervix. In Blaustein's pathology of the female genital tract. $6^{\text {th }}$ Edition. Edits:

Kurman RJ, Ellenson LH, Ronnett BM. Chapter 5, pp194-252.

8. McCredie MR, Sharples KJ, Paul C, Baranyai J, Medley G, Jones RW et al. Natural history of cervical neoplasia and risk of invasive cancer in women with cervical intraepithelial neoplasia 3: a retrospective cohort study. Lancet Oncol. 9(5), 425-34. (2008).

9. zur Hausen H. Papillomaviruses in the causation of human cancers - a brief historical account. Virology. 384(2):260-265 (2009).. doi:10.1016/j.virol.2008.11.046. Epub Jan 8 (2009).

10. Muñoz, N., Bosch, F.X., de Sanjosé, S., et al. The causal link between human papillomavirus and invasive cervical cancer: a population-based case-control study in Columbia and Spain. Int. J. Cancer 52, 743-749. (1992).

11. Bernard HU, Burk RD, Chen Z, van Doorslaer K, Hausen Hz, de Villiers EM. Classification of papillomaviruses (PVs) based on 189 PV types and proposal of taxonomic amendments. Virology. 401(1), 70-79. (2010). Epub (2010) Mar 5.

12. Schiffman $M$, Herrero $R$, Desalle $R$, et al. The carcinogenicity of human papillomavirus types reflects viral evolution. Virology. 20;337(1), 76-84. (2005).

13. Munoz N, Bosch FX, de Sanjose S et al. Epidemiologic classification of human papillomavirus types associated with cervical cancer. The New England Journal of Medicine. 348, 518-527 (2003).

14. Bouvard V, Baan $\mathrm{R}$, Straif $\mathrm{K}$, et al. A review of human carcinogens-part $\mathrm{B}$ : biological agents. Lancet Oncol 10, 321-22. (2009). 
15. De Sanjose S, Quint WG, Alemany L, et al. Human papillomavirus genotype attribution in invasive cervical cancer: a retrospective cross-sectional worldwide study. Lancet Oncol. 11(11), 1048-56 (2010).

16. Narisawa-Saito $M$ \& Kiyono $T$. Basic mechanisms of high-risk human papillomavirus-induced carcinogenesis: roles of E6 and E7 proteins. Cancer Sci. 98, 1505-1511. (2007).

17. Moody CA, Laimins LA. Human papillomavirus oncoproteins: pathways to transformation. Nat Rev Cancer. 10(8), 550-60. (2010).

18. Moyer VA. U.S. Preventive Services Task Force. Screening for cervical cancer: U.S. Preventive Services Task Force recommendation statement. Ann Intern Med. 156(12), 880-91, W312. (2012)

19. Papanicolaou GN, Traut HF. The diagnostic value of vaginal smears in carcinoma of the uterus. Amer J Obs Gyn.42, 193 (1941).

20. Agency for Health Care Policy and Research. Evaluation of cervical cytology. Evidence Report/Technology Assessment No. 5. AHCPR Publication No. 99E010. Rockville (MD): AHCPR; 1999. (Level III)

21. Fahey $M T$, Irwig $L$ \& Macaskill P. Meta-analysis of Pap test accuracy. Am J Epidemiol 14, 680-68 (1995).

22. Hatem F, Wilbur DC. High grade squamous cervical lesions following negative Papanicolaou smears: false-negative cervical cytology or rapid progression. Diagn Cytopathol. 12(2),135-41 (1995).

23. Hartmann KE, Nanda K, Hall S, Myers E. Technologic advances for evaluation of cervical cytology: is newer better? Obstet Gynecol Surv. 56(12), 765-74 (2001).

24. Albrow $\mathrm{R}$, Kitchener $\mathrm{H}$, Gupta N, Desai M. Cervical screening in England: the past, present, and future. Cancer Cytopathol. 120(2), 87-96 (2012).

25. ACOG practice bulletin. Cervical cytology screening. Number 45, August 2003. Int J Gynaecol Obstet. 83, 237-247 (2003).

26. Kitchener HC, Blanks R, Dunn $G$ et al. Automation-assisted versus manual reading of cervical cytology (MAVARIC): a randomised controlled trial. Lancet Oncol. 12(1), 56-64 (2011). Epub Dec 9. (2010).

27. NICE. Technology Appraisal Guidance 69: Guidance on the use of liquid-based cytology for cervical screening. In: National Institue for Clinical Excellence. (2003).

28. Arbyn M, Bergeron C, Klinkhamer P, Martin-Hirsch P, Siebers AG, Bulten J. Liquid compared with conventional cervical cytology: a systematic review and meta-analysis. Obstet Gynecol. 111, 167-77 (2008).

29. Solomon D, Davey D, Kurman R. et al. Forum Group Members; Bethesda 2001 Workshop. The 2001 Bethesda System: terminology for reporting results of cervical cytology. JAMA. 287(16), 2114-9 (2002).

30. Evans DM, Hudson EA, Brown CL et al. Terminology in gynaecological cytopathology: report of the Working Party of the British Society for Clinical Cytology. J. Clin. Pathol. 39, 933-944 (1986). 
31. Denton KJ, Herbert A, Turnbull LS et al. British Society of Clinical Cytology. The revised BSCC terminology for abnormal cervical cytology. Cytopathology. 19(3),137-157 ( 2008).

32. NHSCSP Publication No. 1. Achievable standards, Benchmarks for reporting, and Criteria for evaluating cervical cytopathology. Third Edition, June 2012.

33. Cronjé HS. Screening for cervical cancer in the developing world. Best Pract. Res. Clin .Obstet. Gynaecol. 19, 517-529 (2005).

34. Sankaranarayanan R, Nessa A, Esmy PO, Dangou JM. Visual inspection methods for cervical cancer prevention. Best Pract. Res. Clin. Obstet. Gynaecol. 26(2), 221-232 (2012).

35. Sauvaget C, Fayette JM, Muwonge R, Wesley R, Sankaranarayanan R. Accuracy of visual inspection with acetic acid for cervical cancer screening. Int. J. Gynaecol. Obstet. 113(1), 14-24 (2011).

36. Sankaranarayanan R, Esmy PO, Rajkumar R et al. Effect of visual screening on cervical cancer incidence and mortality in Tamil Nadu, India: a clusterrandomised trial. Lancet 370 (9585), 398-406 (2007).

37. Walboomers JM, Jacobs MV, Manos MM et al. Human papillomavirus is a necessary cause of invasive cervical cancer worldwide. J Pathol. 189, 12-9 (1999).

38. Cuzick J, Clavel C, Petry KU et al. Overview of the European and North American studies on HPV testing in primary cervical cancer screening. Int $\mathrm{J}$ Cancer. 119, 1095-1101 (2006).

39. Mayrand MH, Duarte-Franco E, Rodrigues I, et al . Human papillomavirus DNA versus Papanicolaou screening tests for cervical cancer . N. Engl. J. Med.; 357 (16), $1579-1588$ (2007).

40. Zhao FH, Lin MJ, Chen F et al. Cervical Cancer Screening Group in China. Performance of high-risk human papillomavirus DNA testing as a primary screen for cervical cancer: a pooled analysis of individual patient data from 17 population-based studies from China. Lancet Oncol.. 11, 1160-1171 (2010).

41. Arbyn M, Sasieni P, Meijer CJ, et al. Chapter 9: Clinical applications of HPV testing: a summary of meta-analyses. Vaccine 24 (suppl 3), 78-89 (2006).

42. Koliopoulos G, Arbyn M, Martin-Hirsch P, Kyrgiou M, Prendiville W, Paraskevaidis E. Diagnostic accuracy of human papillomavirus testing in primary cervical screening: a systematic review and meta-analysis of nonrandomized studies. Gynecol Oncol 104, 232-46 (2007).

43. Bulkmans NW, Berkhof $J$, Rozendaal $L$ et al. Human papillomavirus DNA testing for the detection of cervical intraepithelial neoplasia grade 3 and cancer: 5-year follow-up of a randomised controlled implementation trial. Lancet. 370(9601),1764-1772 (2007).

44. Rijkaart DC, Berkhof J, Rozendaal L, van Kemenade FJ, Bulkmans NW, HeidemanDA, Kenter GG, Cuzick J, Snijders PJ, Meijer CJ. Human papillomavirus testing for the detection of high-grade cervical intraepithelial neoplasia and cancer: final results of the POBASCAM randomised controlled trial. Lancet Oncol. 13, 78-88 (2012). 
45. Ronco G, Giorgi-Rossi P, Carozzi F et al. New Technologies for Cervical Cancer screening (NTCC) Working Group. Efficacy of human papillomavirus testing for the detection of invasive cervical cancers and cervical intraepithelial neoplasia: a randomised controlled trial. Lancet Oncol. 11(3), 249-257 (2010).

46. Moyer VA; U.S. Preventive Services Task Force. Screening for cervical cancer: U.S. Preventive Services Task Force recommendation statement. Ann Intern Med. 156(12), 880-891, W312 (2012).

47. Rossi PG, Ronco G. The Present and Future of Cervical Cancer Screening Programmes in Europe. Curr Pharm Des. Sep 24. [Epub ahead of print] (2012).

48. Legood R, Gray A, Wolstenholme J, Moss S Lifetime effects, costs, and cost effectiveness of testing for human papillomavirus to manage low grade cytological abnormalities: results of the NHS pilot studies. BMJ 332(7533), 7985 (2006).

49. Moss S, Gray A, Legood R, Vessey M, Patnick J, Kitchener H. Effect of testing for human papillomavirus as a triage during screening for cervical cancer: observational before and after study. BMJ 332(7533), 83-85 (2006).

50. Kelly RS, Patnick J, Kitchener HC, Moss SM; NHSCSP HPV Special Interest Group. HPV testing as a triage for borderline or mild dyskaryosis on cervical cytology: results from the Sentinel Sites study. Br. J. Cancer. 105(7), 983-988 (2011). doi: 10.1038/bjc.2011.326.

51. ACOG Practice Bulletin Clinical management guidelines for obstetriciangynaecologists No 109 Cervical cytology screening. Dec 2009.

52. IARC. World Cancer Report 2008: IARC; 2008

53. Stoler $\mathrm{MH}$, Wright TC Jr, Sharma A, et al. High-risk human papillomavirus testing in women with ASC-US cytology:results from the ATHENA HPV study. Am. J. Clin Pathol. 135, 468-475 (2011)

54. Wright TC Jr, Stoler MH, Sharma A, Zhang G, Behrens C, Wright TL; ATHENA (Addressing THE Need for Advanced HPV Diagnostics) Study Group. Evaluation ofHPV-16 and HPV-18 genotyping for the triage of women with highrisk HPV+cytology-negative results. Am. J. Clin. Pathol. 36(4), 578-586 (2011)

55. Wright TC Jr, Stoler MH, Behrens CM, Apple R, Derion T, Wright TL. The ATHENA human papillomavirus study: design, methods, and baseline results. Am. J. Obstet. Gynecol. 206(1), 46.e1-46.e11 (2012). Epub Jul 22 (2011).

56. Arbyn M, Roelens J, Cuschieri K, Cuzick J, Szarewski A, Ratnam S, Reuschenbach M, Belinson S, Belinson JL, Monsonego J. The APTIMA HPV assay versus the hybrid capture 2 test in triage of women with ASC-US or LSIL cervical cytology: A meta-analysis of the diagnostic accuracy. Int. J. Cancer. May 18. doi: 10.1002/ijc.27636. [Epub ahead of print] (2012).

57. Ratnam S, Coutlee F, Fontaine D et al. Aptima HPV E6/E7 mRNA test is as sensitive as Hybrid Capture 2 Assay but more specific at detecting cervical precancer and cancer. J Clin Microbiol. 49(2), 557-564 (2011).

58. Teschendorff AE, Jones A, Fiegl $\mathrm{H}$ et al. Epigenetic variability in cells of normal cytology is associated with the risk of future morphological transformation. Genome Med. 4(3), 24 (2012). 
59. Brown AJ, Trimble CL. New technologies for cervical cancer screening. Best Pract Res Clin. Obstet. Gynaecol... 26, 233-42 (2012).

60. Kitchener HC, Gilham C, Sargent A et al. A comparison of HPV DNA testing and liquid based cytology over three rounds of primary cervical screening: extended follow up in the ARTISTIC trial. Eur. J. Cancer. 47:864-71 (2011). Epub Feb 18 (2011).

61. Sankaranarayanan R, Nene BM, Shastri SS et al. HPV screening for cervical cancer in rural India. N. Engl. J. Med. 360(14),1385-1394 (2009).

62. Denny LA, Wright TC Jr. Human papillomavirus testing and screening. Best Pract. Res. Clin. Obstet. Gynaecol. 19(4), 501-515 (2005).

63. Qiao YL, Sellors JW, Eder PS et al. A new HPV-DNA test for cervical-cancer screening in developing regions: a cross-sectional study of clinical accuracy in rural China. Lancet Oncol. 9, 929-936 (2008).

64. Petignat $P$, Vassilakos $P$. Is it time to introduce HPV self-sampling for primary cervical cancer screening? J. Natl. Cancer Inst. 104(3), 166-167 (2012).

doi:10.1093/jnci/djr544. Epub Jan 23 (2012).

65. Petignat $P$, Faltin DL, Bruchim I, Tramèr MR, Franco EL, Coutlée F. Are selfcollected samples comparable to physician-collected cervical specimens for human papillomavirus DNA testing? A systematic review and meta-analysis. Gynecol. Oncol. 105, 530-5 (2007).

66. Zhao FH, Lewkowitz AK, Chen F et al. Pooled analysis of a self-sampling HPV DNA Test as a cervical cancer primary screening method. J. Natl. Cancer Inst. 104, 178-88 (2012).

67. Wise J. Pilot study will assess whether HPV test should replace smears to screen for cervical cancer. BMJ. May 28;344:e3744. doi: 10.1136/bmj.e3744 (2012).

68. World Health Organization: Human papillomavirus vaccines. WHO position paper. Wkly. Epidemiol. Rec. 84, 118-131 (2009).

69. Tay SK. Cervical cancer in the human papillomavirus vaccination era. Curr. Opin. Obstet. Gynecol. 24(1), 3-7 (2012).

70. Goldie SJ, Gaffikin L, Goldhaber-Fiebert et al. Alliance for Cervical Cancer Prevention Cost Working Group. Cost-effectiveness of cervical-cancer screening in five developing countries. N. Engl. J. Med. 353, 2158-2168 (2005).

71. Elit L, Jimenez W, McAlpine J, Ghatage P, Miller D, Plante M. Cervical cancer prevention in low-resource settings. J. Obstet. Gynaecol. Can. 33, 272-279 (2011).

72. Basu P, Nessa A, Majid M, Rahman JN, Ahmed T. Evaluation of the National Cervical Cancer Screening Programme of Bangladesh and the formulation of quality assurance guidelines. J. Fam. Plann. Reprod. Health Care 36,131-134 (2010).

73. Manchanda R, Menon U. Screening for gynaecological malignancy. In Ali Ayhan, Murat Gultekin, Polat Dursun (ed.) Textbook of gynaecological oncology. Ankara: Günes Publishing 2nd edition. 124-134 (2011). 
74. Bast Jr. R. C. Molecular approaches to personalizing management of ovarian cancer. Annals of Oncology 22 (Supplement 8): viii5-viii15, 2011doi:10.1093/annonc/mdr516

75. Campbell S, Goessens L, Goswamy R, and Whitehead, M. Real-time ultrasonography for determination of ovarian morpholoy and volume, Lancet 1 , 425-426 (1982).

76. DePriest PD, Gallion HH, Pavlik EJ, Kryscio RJ, van Nagell JR Jr. Transvaginal sonography as a screening method for the detection of early ovarian cancer. Gynecol. Oncol. 65, 408-414 (1997).

77. Higgins RV, van Nagell JR Jr, Donaldson ES et al. Transvaginal sonography as a screening method for ovarian cancer. Gynecol. Oncol. 34, 402-406 (1989).

78. Higgins RV, van Nagell JR Jr, Woods $\mathrm{CH}$, Thompson EA, Kryscio RJ. Interobserver variation in ovarian measurements using transvaginal sonography. Gynecol Oncol. 39, 69-71 (1990).

79. Bignardi T, Condous G. Ultrasound for ovarian cancer screening: are we throwing the baby out with the bath water? Gynecol. Obstet. Invest. 71(1), 4146 (2011).

80. Timmerman D, Ameye L, Fischerova $D$ et al. Simple ultrasound rules to distinguish between benign and malignant adnexal masses before surgery: prospective validation by IOTA group. BMJ. Dec 14;341:c6839. doi: 10.1136/bmj.c6839. (2010).

81. van Nagell JR Jr, Miller RW, DeSimone CP et al. Long-term survival of women with epithelial ovarian cancer detected by ultrasonographic screening. Obstet. Gynecol. 118, 1212-1221 (2011).

82. Thériault $\mathrm{C}$, Pinard M, Comamala $\mathrm{M}$ et al. MUC16 (CA125) regulates epithelial ovarian cancer cell growth, tumorigenesis and metastasis. Gynecol. Oncol. 121(3), 434-443 (2011).

83. Bast RC, Jr., Feeney M, Lazarus H, Nadler LM, Colvin RB, Knapp RC. Reactivity of a monoclonal antibody with human ovarian carcinoma. J. Clin. Invest. 68, 1331-1337 (1981).

84. Patankar MS, Jing Y, Morrison JC et al. Potent suppression of natural killer cell response mediated by the ovarian tumor marker CA125. Gynecol. Oncol. 99(3), 704-713. (2005).

85. Davelaar EM, van Kamp GJ, Verstraeten RA, Kenemans P. Comparison of seven immunoassays for the quantification of CA 125 antigen in serum. Clin. Chem, 44(7), 1417-1422 (1998).

86. Bast Jr. RC, Klug TL, St John E et al. A radioimmunoassay using a monoclonal antibody to monitor the course of epithelial ovarian cancer. N. Engl. J. Med. 309, 883 -887 (1983).

87. Alagoz T, Buller RE, Berman M, Anderson B, Manetta A, DiSaia P. What is a normal CA125 level? Gynecol. Oncol. 53, 93-97 (1994)

88. Skates SJ, Mai P, Horick NK et al. Large prospective study of ovarian cancer screening in high-risk women: CA125 cut-point defined by menopausal status. Cancer Prev. Res. (Phila). 4, 1401-1408 (2011). 
89. Jacobs I, Bast RC, Jr. The CA 125 tumour-associated antigen: a review of the literature. Hum Reprod 4: 1-12 (1989).

90. Zurawski VR, Jr., Orjaseter H, Andersen A, Jellum E. Elevated serum CA 125 levels prior to diagnosis of ovarian neoplasia: relevance for early detection of ovarian cancer. Int. J. Cancer 42: 677-80 (1988).

91. Jacobs I, Davies AP, Bridges J et al. Prevalence screening for ovarian cancer in postmenopausal women by CA 125 measurement and ultrasonography. BMJ. 306(6884), 1030-1034 (1993).

92. Jacobs IJ, Skates S, Davies AP et al. Risk of diagnosis of ovarian cancer after raised serum CA 125 concentration: a prospective cohort study. BMJ 313(7069), 1355-1358 (1996).

93. Skates SJ PD, Jacobs IJ. Screening based on the risk of cancer calculation from Bayesian hierarchical change point and mixture models of longitudinal markers. J. Am. Stat. Assoc. 96, 429-43 (2001).

94. Skates SJ, Menon U, MacDonald N et al. Calculation of the Risk of Ovarian Cancer From Serial CA-125 Values for Preclinical Detection in Postmenopausal Women. J. Clin. Oncol. 21(10 Suppl), 206-210 (2003).

95. Menon U, Skates SJ, Lewis S et al. Prospective study using the risk of ovarian cancer algorithm to screen for ovarian cancer. J. Clin. Oncol. 23(31), 79197926. (2005).

96. Greene $\mathrm{MH}$, Piedmonte $\mathrm{M}$, Alberts $\mathrm{D}$ et al. A prospective study of risk-reducing salpingo-oophorectomy and longitudinal CA-125 screening among women at increased genetic risk of ovarian cancer: design and baseline characteristics: a Gynecologic Oncology Group study. Cancer Epidemiol. Biomarkers Prev. 17, 594-604 (2008).

97. Menon U, Gentry-Maharaj A, Hallett $R$ et al. Sensitivity and specificity of multimodal and ultrasound screening for ovarian cancer, and stage distribution of detected cancers: results of the prevalence screen of the UK Collaborative Trial of Ovarian Cancer Screening (UKCTOCS). Lancet Oncol. 10(4):327-340 (2009).

98. Cramer DW, Bast RC, Jr., Berg CD et al. Ovarian cancer biomarker performance in prostate, lung, colorectal, and ovarian cancer screening trial specimens. Cancer Prev. Res. (Phila) 4, 365-74 (2011)

99. Van Gorp T, Cadron I, Despierre E et al. HE4 and CA125 as a diagnostic test in ovarian cancer: prospective validation of the Risk of Ovarian Malignancy Algorithm. Br. J. Cancer.104(5), 863-870 ( 2011).

100. Montagnana M, Lippi G, Ruzzenente et al. The utility of serum human epididymis protein 4 (HE4) in patients with a pelvic mass. J. Clin. Lab. Anal. 23(5), 331-335. (2009).

101. Jacobs IJ, Skates SJ, MacDonald N et al. Screening for ovarian cancer: a pilot randomised controlled trial. Lancet 353, 1207-10 (1999).

102. Kobayashi $\mathrm{H}$, Yamada $\mathrm{Y}$, Sado $\mathrm{T}$ et al. A randomized study of screening for ovarian cancer: a multicenter study in Japan. Int. J. Gynecol. Cancer 18(3):41420 (2008). Epub Jul 21 (2007). 
103. Buys SS, Partridge E, Black A et al. Effect of screening on ovarian cancer mortality: the Prostate, Lung, Colorectal and Ovarian (PLCO) Cancer Screening Randomized Controlled Trial. JAMA. 305, 2295-2303 (2011).

104. Menon U, Gentry-Maharaj A, Jacobs I. Ovarian Cancer Screening and Mortality. JAMA. 306(14), 1544-1545 (2011); doi:10.1001/jama.2011.1461.

105. Menon U. Ovarian cancer screening has no effect on disease-specific mortality. Evid. Based Med. 17(2), 47-48 (2012); doi: 10.1136/ebm.2011.100163. Epub Sep 26 (2011).

106. Pinsky PF, Zhu C, Skates SJ, et al. Potential effect of the risk of ovarian cancer algorithm (ROCA) on the mortality outcome of the Prostate, Lung, Colorectal and Ovarian (PLCO) trial. Int. J. Cancer. 2012 Oct 15. doi: 10.1002/ijc.27909. [Epub ahead of print].

107. Fallowfield L, Fleissig A, Barrett J et al. Awareness of ovarian cancer risk factors, beliefs and attitudes towards screening: baseline survey of 21,715 women participating in the UK Collaborative Trial of Ovarian Cancer Screening. Br. J. Cancer. 103(4),454-61 (2010).

108. Jacobs I, Menon U. Can ovarian cancer screening save lives? The question remains unanswered. Obstet. Gynecol. 118(6), 1209-11. (2011). doi: 10.1097/AOG.0b013e31823b49b3.

109. Evans DG, Gaarenstroom KN, Stirling D et al.. Screening for familial ovarian cancer: poor survival of BRCA1/2 related cancers. J. Med. Genet. 46, 593-597 (2009).

110. Rosenthal AN, Fraser L, Manchanda R et al. Results of annual screening in phase I of the United Kingdom familial ovarian cancer screening study highlight the need for strict adherence to screening schedule. J. Clin. Oncol. 31(1), 4957. (2013) doi: 10.1200/JCO.2011.39.7638. Epub Dec 3 (2012).

111. Manchanda R, Rosenthal A, Burnell M, Fraser L, Mackay J, Skates S. Change in stage distribution observed with annual screening for ovarian cancer in BRCA carriers. J. Med. Genet. 46, 423-424 ( 2009).

112. K. H. Lu, S. Skates, T. B. Bevers, W. et al. A prospective U.S. ovarian cancer screening study using the risk of ovarian cancer algorithm (ROCA). J. Clin. Oncol. 28:15s, (suppl; abstr 5003) 2010).

113. Goff BA, Mandel L, Muntz HG, Melancon CH. Ovarian carcinoma diagnosis. Cancer. 89(10), 2068-2075 (2000).

114. Olson SH, Mignone L, Nakraseive C, Caputo TA, Barakat RR, Harlap S.Symptoms of ovarian cancer. Obstet. Gynecol. 98(2), 212-217 (2001).

115. Goff BA, Mandel LS, Melancon CH, Muntz HG. Frequency of symptoms of ovarian cancer in women presenting to primary care clinics. JAMA. 291(22), 2705-2712. 2004).

116. Olaitan A. NICE on ovarian cancer. Recommendations for detection in primary care are flawed. BMJ. 342:d3022. doi: 10.1136/bmj.d3022 (2011).

117. Cave JA NICE on ovarian cancer. Please include GPs in developing guidelines. BMJ. 342:d3023. doi: 10.1136/bmj.d3023. (2011). 
118. Goff BA, Mandel LS, Drescher CW et al. Development of an ovarian cancer symptom index: possibilities for earlier detection. Cancer. 109(2), 221-227. (2007).

119. Andersen MR, Goff BA, Lowe KA et al. Use of a Symptom Index, CA125, and HE4 to predict ovarian cancer. Gynecol. Oncol. 116(3), 378-83 (2010). Epub Nov 28 (2009).

120. Gilbert L, Basso O, Sampalis J et al. DOvE Study Group. Assessment of symptomatic women for early diagnosis of ovarian cancer: results from the prospective DOvE pilot project. Lancet Oncol. 13(3), 285-291 (2012).

121. Burnell M, Gentry-Maharaj A, Ryan A et al. Impact on mortality and cancer incidence rates of using random invitation from population registers for recruitment to trials. Trials. 12:61. (2011) doi: 10.1186/1745-6215-12-61.

122. Moyer VA, on behalf of the USPSTF. Screening for Ovarian Cancer: U.S. Preventive Services Task Force Reaffirmation Recommendation Statement. Annals of Internal Medicine. 2012. Sep 11. Doi: 10.7326/0003-4819-157-11201212040-00539 [Epub ahead of print].

123. Brown PO, Palmer $C$. The preclinical natural history of serous ovarian cancer: defining the target for early detection. PLoS Med. 6 (7):e1000114. (2009).

124. Hori SS, Gambhir SS. Mathematical model identifies blood biomarker-based early cancer detection strategies and limitations. Sci Transl Med 3 (109):109ra116. (2011).

125. Vaughan S, Coward Jl, Bast RC Jr et al. Rethinking ovarian cancer: recommendations for improving outcomes. Nat. Rev. Cancer. 11(10), 719-725. (2011). doi: 10.1038/nrc3144.

126. Lee $\mathrm{Y}$, Miron A, Drapkin R et al. A candidate precursor to serous carcinoma that originates in the distal fallopian tube. J. Pathol. 211(1), 26-35 (2007).

127. Carlson J, Roh MH, Chang MC, Crum CP. Recent advances in the understanding of the pathogenesis of serous carcinoma: the concept of lowand high-grade disease and the role of the fallopian tube. Diagn Histopathol (Oxf). 14(8), 352-365 (2008).

128. Mehra K, Mehrad M, Ning G et al. STICS, SCOUTs and p53 signatures; a new language for pelvic serous carcinogenesis. Front Biosci (Elite Ed). 3, 625-634 (2011).

129. McAlpine JN, El Hallani S, Lam SF et al. Autofluorescence imaging can identify preinvasive or clinically occult lesions in fallopian tube epithelium: a promising step towards screening and early detection. Gynecol. Oncol. 120(3), 385-392 (2011). Epub 2011 Jan 14.

130. Prat J. Ovarian carcinomas: five distinct diseases with different origins, genetic alterations, and clinicopathological features. Virchows Arch. 460(3), 237-49 (2012). doi: 10.1007/s00428-012-1203-5. Epub Feb 10 (2012).

131. Kohn EC, Hurteau J. Ovarian cancer : Making its own rules-again. Cancer. 2012 Dec 11. doi: 10.1002/cncr.27833. [Epub ahead of print] 
132. Grisham RN, lyer G, Garg K et al. BRAF Mutation is associated with early stage disease and improved outcome in patients with low-grade serous ovarian cancer. Cancer. doi:10.1002/cncr.27782 (2012).

133. Kurman RJ, Shih leM. The origin and pathogenesis of epithelial ovarian cancer: a proposed unifying theory. Am. J. Surg. Pathol. 34:433-443 (2010).

134. Kurman RJ, Shih leM. Molecular pathogenesis and extraovarian origin of epithelial ovarian cancer--shifting the paradigm. Hum. Pathol. 42 (7), 918-931 (2011).

135. Kinde I, Bettegowda C, Wang Y, et al . Evaluation of DNA from the papanicolaou test to detect ovarian and endometrial cancers. Sci Transl Med. 5(167), 167ra4. doi: 10.1126/scitranslmed.3004952. (2013).

136. Sorosky JI. Endometrial cancer. Obstet. Gynecol. 120(2 Pt 1), 383-397 (2012).

137. Evans T, Sany O, Pearmain P, Ganesan R, Blann A, Sundar S. Differential trends in the rising incidence of endometrial cancer by type: data from a UK population-based registry from 1994 to 2006. Br J Cancer. 26;104, 1505-1510. (2011).

138. Jacobs I, Gentry-Maharaj A, Burnell $M$ et al. Sensitivity of transvaginal ultrasound screening for endometrial cancer in postmenopausal women: a case-control study within the UKCTOCS cohort. Lancet Oncol. 12(1), 38-48 (2011).

139. Lindemann K, Vatten LJ, Ellstrom-Engh M, Eskild A. Body mass, diabetes and smoking, and endometrial cancer risk: a follow-up study. $\mathrm{Br} \mathrm{J}$ Cancer 98,15821585 (2008).

140. Reeves GK, Pirie K, Beral V, Green J, Spencer E, Bull D. Cancer incidence and mortality in relation to body mass index in the Million Women Study: cohort study. BMJ. 335:1134 (2007).

141. Bokhman JV. Two pathogenetic types of endometrial carcinoma. Gynecol. Oncol.15(1), 10-17 (1983).

142. Allard JE, Maxwell GL. Race disparities between black and white women in the incidence, treatment, and prognosis of endometrial cancer. Cancer Control. 2009 Jan;16(1):53-6.

143. Lynch, H.T., Krush, A.J. The cancer family syndrome and cancer control. Surg. Gynecol. Obstet. 132, 247-250 (1971).

144. Lynch HT, Smyrk T. Hereditary nonpolyposis colorectal cancer (Lynch syndrome)an updated review Cancer $78,1149-1167$ (1996).

145. Vasen, HF, Watson P, Mecklin, JP Lynch HT. New clinical criteria for hereditary nonpolyposis colorectal cancer (HNPCC, Lynch syndrome) proposed by the International Colaboratory Group on HNPCC. Gastroenterology 116, 14531456 (1999).

146. Umar A, Boland CR, Terdiman JP et al. Revised Bethesda Guidelines for hereditary nonpolyposis colorectal cancer (Lynch syndrome) and microsatellite instability. J. Natl. Cancer Inst. 96(4), 261-268 (2004).

147. Watson P, Riley B. The tumor spectrum in the Lynch syndrome. Fam. Cancer. 4, 245-248 (2005). 
148. Pande $\mathrm{M}$, Wei $\mathrm{C}$, Chen $\mathrm{J}$ et al. Cancer spectrum in DNA mismatch repair gene mutation carriers: results from a hospital based Lynch syndrome registry. Fam. Cancer. 11(3), 441-447 (2012).

149. Stuckless S, Green J, Dawson L et al. Impact of gynecological screening in Lynch syndrome carriers with an MSH2 mutation. Clin. Genet. 2012 Jul 6. doi: 10.1111/j.1399-0004.2012.01929.x. [Epub ahead of print].

150. Stoffel E, Mukherjee B, Raymond VM et al. Calculation of risk of colorectal and endometrial cancer among patients with Lynch syndrome. Gastroenterology. 137(5), 1621-1627 (2009). Epub 2009 Jul 18.

151. Bonadona V, Bonaïti B, Olschwang S et al. French Cancer Genetics Network. Cancer risks associated with germline mutations in $\mathrm{MLH} 1, \mathrm{MSH} 2$, and MSH6 genes in Lynch syndrome. JAMA. 305(22), 2304-2310. (2011).

152. Nakagawa-Okamura $C$, Sato $S$, Tsuji I, et al. Effectiveness of mass screening for endometrial cancer. Acta Cytol. 46(2), 277-283 (2002).

153. Rijcken FE, Mourits MJ, Kleibeuker JH, Hollema H, van der Zee AG. Gynecologic screening in hereditary nonpolyposis colorectal cancer. Gynecol. Oncol. 91(1), $74-80$ (2003).

154. Lecuru F, Le Frere Belda MA, Bats AS et al. Performance of office hysteroscopy and endometrial biopsy for detecting endometrial disease in women at risk of human non-polyposis colon cancer: a prospective study. Int. J. Gynecol. Cancer 18(6), 1326-1331 (2008).

155. Gerritzen LH, Hoogerbrugge N, Oei AL et al. Improvement of endometrial biopsy over transvaginal ultrasound alone for endometrial surveillance in women with Lynch syndrome. Fam. Cancer 8(4), 391-397 (2009).

156. Hendriks $\mathrm{YM}$, de Jong $\mathrm{AE}$, Morreau $\mathrm{H}$ et al. Diagnostic approach and management of Lynch syndrome (hereditary nonpolyposis colorectal carcinoma): a guide for clinicians. CA Cancer J. Clin. 56(4), 213-225 (2006).

157. Lindor NM, Petersen GM, Hadley DW et al. Recommendations for the care of individuals with an inherited predisposition to Lynch syndrome: a systematic review. JAMA 296(12), 1507-1517 (2006).

158. Dijkhuizen FP, Mol BW, Brolmann HA, Heintz AP. The accuracy of endometrial sampling in the diagnosis of patients with endometrial carcinoma and hyperplasia: a meta-analysis. Cancer 89, 1765-72 (2000).

159. Elmasry K, Davies AJ, Evans DG, Seif MN, Reynolds K. Strategies for endometrial screening in the Lynch syndrome population: a patient acceptability study. Fam. Cancer 8, 431-439 (2009)

160. Wood NJ, Munot S, Sheridan E, Duffy SR. Does a "one-stop" gynecology screening clinic for women in hereditary nonpolyposis colorectal cancer families have an impact on their psychological morbidity and perception of health? Int. J. Gynecol. Cancer. 18: 279-284. (2008)

161. Pasqualotto EB, Margossian H, Price LL, Bradley LD. Accuracy of preoperative diagnostic tools and outcome of hysteroscopic management of menstrual dysfunction. J. Am. Assoc. Gynecol. Laparosc. 7 ,201-209 (2000). 
162. Tahir MM, Bigrigg MA, Browning JJ, Brookes ST, Smith PA. A randomised controlled trial comparing transvaginal ultrasound, outpatient hysteroscopy and endometrial biopsy with inpatient hysteroscopy and curettage. Br. J. Obstet. Gynaecol. 106: 1259-64 (1999).

163. Lecuru F, Metzger U, Scarabin C, Le Frere Belda MA, Olschwang S, Laurent Puig P. Hysteroscopic findings in women at risk of HNPCC. Results of a prospective observational study. Fam. Cancer 6, 295-9 (2007).

164. Manchanda R, Saridogan E, Abdelraheim A et al. Annual outpatient hysteroscopy and endometrial sampling (OHES) in HNPCC/Lynch syndrome (LS). Arch. Gynecol. Obstet. 286(6), 1555-1562 (2012). [Epub ahead of print] Aug 4. (2012).

\section{Websites}

201. http://globocan.iarc.fr/ accessed $25^{\text {th }}$ July 2012.

202. http://www.cancerscreening.nhs.uk/cervical/ NHSCSP 2011 assessed July 2012.

203. http://www.cancerscreening.nhs.uk/cervical/publications/nhscsp20.pdf

204. http://www.cancerresearchuk.org/cancerinfo/cancerstats/types/cervix/incidence/\#sourc $\underline{\mathrm{e} 16}$

205. Cancer Research - UK http://www.cancerresearchuk.org/cancer info/cancerstats/types/ovary/

206. Department of Health. Ovarian Cancer: Key messages for health professionals, 2009. http://www.dh.gov.uk/en/Healthcare/Cancer/index.htm

207. Department of Health. Ovarian cancer: Key messages for the public http://www.dh.gov.uk/prod consum dh/groups/dh digitalassets/documents/digitalasse t/dh 110533.pdf

208. http://www.cancerresearchuk.org/cancer-info/cancerstats/types/ovary/survival/ovariancancer-survival-statistics

209. UKFOCSS. United Kingdom Familial Ovarian Cancer Screening Study. In: http://www.instituteforwomenshealth.ucl.ac.uk/academic research/gynaecologicalcanc er/gcrc/ukfocss/

210. A Trial Using Novel Markers to Predict Malignancy in Elevated-Risk Women. http://clinicaltrials.gov/ct2/show/NCT01121640 (2010)

211. Fujirebio Diagnostics Inc http://www.he4test.com/row/professionals/index.html

212. http://www.wcn.org/downloads/GCF Press Release June2007.pdf

213. Eve appeal in partnership with Ovacome. Ovarian Cancer UK Consensus Statement, 2008. http://www.eveappeal.org.uk/media/42343/cs_ovarian.pdf

214. NICE Clinical Guideline 122 http://www.nice.org.uk/nicemedia/live/13464/54194/54194.pdf

215. http://www.cancerresearchuk.org/cancer-info/cancerstats/types/uterus/

216. http://www.cancerresearchuk.org/cancer-info/news/archive/pressrelease/2012-04-05womb-cancer-deaths-rise-by-a-fifth-in-last-decade.

217. http://www.cancerresearchuk.org/cancer-info/cancerstats/types/uterus/survival/uteruscancer-survival-statistics\#one 
